\title{
Optical and Structural Properties of Thermally Evaporated Zinc Oxide Thin Films on Polyethylene Terephthalate Substrates
}

\author{
M. G. Faraj and K. Ibrahim \\ Nano-Optoelectronics Research and Technology Laboratory (N.O.R), School of Physics, Universiti Sains Malaysia, \\ 11800 Penang, Malaysia \\ Correspondence should be addressed to M. G. Faraj, mohphysics_79@yahoo.com
}

Received 26 July 2011; Revised 3 September 2011; Accepted 8 September 2011

Academic Editor: Jan-Chan Huang

Copyright ( $) 2011$ M. G. Faraj and K. Ibrahim. This is an open access article distributed under the Creative Commons Attribution License, which permits unrestricted use, distribution, and reproduction in any medium, provided the original work is properly cited.

Zinc oxide thin films of different thicknesses ranging from 100 to $300 \mathrm{~nm}$ were prepared on polyethylene terephthalate substrates with thermal evaporation in a vacuum of approximately $3 \times 10^{-5}$ Torr. X-ray diffraction patterns confirm the proper phase formation of the material. From atomic force microscopy (AFM) images, it was found that the root mean square roughness of the film surface increased as the film thickness increased. The optical properties of $\mathrm{ZnO}$ on PET substrates were determined through the optical transmission method using an ultraviolet-visible spectrophotometer. The optical band gap values of $\mathrm{ZnO}$ thin films slightly decreased as the film thickness increased.

\section{Introduction}

Zinc oxide $(\mathrm{ZnO})$ is an important wide band gap II-VI semiconductor material and a natural n-type electrical conductor. $\mathrm{ZnO}$ thin films are used in various applications, such as in transparent conductive film and window materials in solar cell applications, because of its high optical transmittance in the visible light region [1]. Recently, $\mathrm{ZnO}$ materials have attracted much more interest for the application of optoelectronic devices, such as light-emitting diodes, laser diodes, piezoelectric transducers, transistors, bulk acoustic wave devices, acoustic-optical devices, and phosphors [2].

There are different methods available to prepare zinc oxide, such as radio-frequency magnetron sputtering [3], chemical vapor deposition [4], the sol-gel method [5], atomic layer deposition [6], spray pyrolysis [7], pulsed laser deposition [8], and thermal evaporation [9]. Of the various methods, the vacuum evaporation technique is known to be suitable for the preparation of $\mathrm{ZnO}$ films for a wide range of applications.

This movement towards flexible polymer substrates is gaining a great amount of interest [10-12] because they can provide advantages such as light weight, high shock resistance and scalable roll-to-roll preparation procedures. Polyethylene terephthalate (PET) has been selected as a substrate in this study because PET is a low-cost, hightransmission material.

In this present work, the structural and optical properties of $\mathrm{ZnO}$ thin films with different thicknesses ranging from 100 to $300 \mathrm{~nm}$ and grown by the thermal evaporation technique on PET substrates were studied. The effects of thickness on the optical properties of the prepared films were also studied.

\section{Experimental Details}

In this experiment, $250 \mu \mathrm{m}$ thick PET substrates obtained from Penfibre Sdn. Bhd. (Film Division) were used. The PET substrates were first cleaned by full immersion in Decon 90 at room temperature $\left(25^{\circ} \mathrm{C}\right)$ for 10 minutes to remove contamination. After the cleaning process, all of the substrates were rinsed with deionized water (DIW) to remove the Decon 90 residue. The samples were then dipped in isopropyl alcohol (IPA) at room temperature $\left(25^{\circ} \mathrm{C}\right)$ and 


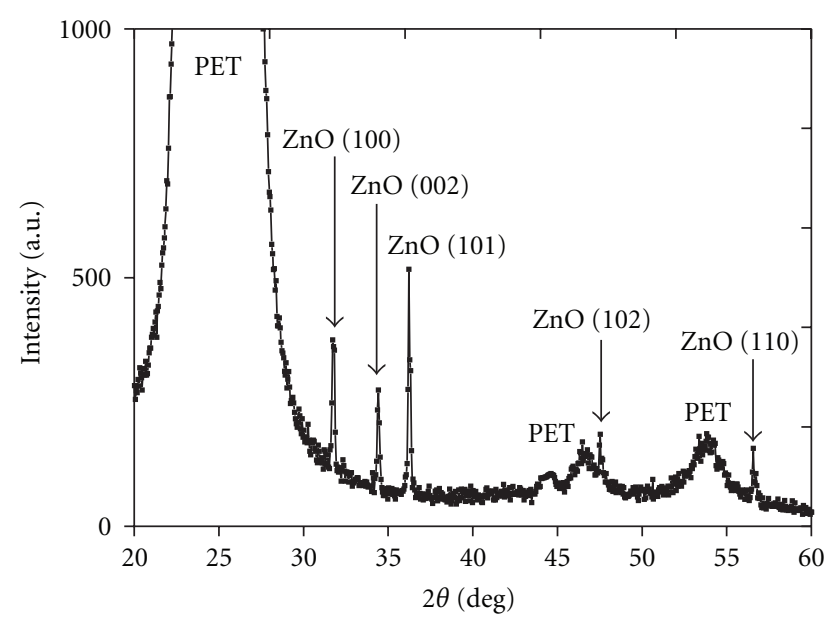

FIgURE 1: XRD patterns of $\mathrm{ZnO}$ thin films on PET substrates.

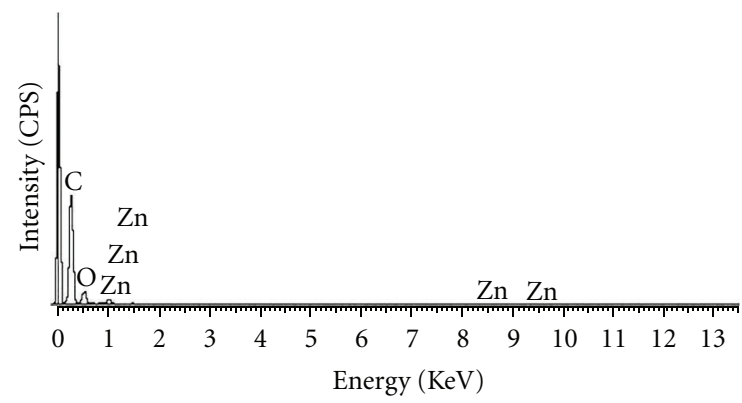

Figure 2: EDX results for $\mathrm{ZnO}$ thin films deposited on PET substrates.

agitated with moderate ultrasonic power for 10 minutes. The samples were again dipped in DIW and then dried off with nitrogen $\left(\mathrm{N}_{2}\right)$ gas after the ultrasonic cleaning.

$\mathrm{ZnO}$ thin films varying in thicknesses between 100 and $300 \mathrm{~nm}$ were prepared on PET substrates by the thermal evaporation technique in a vacuum of $3 \times 10^{-5}$ Torr. The evaporator system, an Edwards Auto306, utilizes a common diffusion and rotary pump to evacuate the high vacuum chamber, which was made of an enclosed bell jar. Wafers were loaded at the top of the vacuum chamber while a tungsten boat was used to hold the molten $\mathrm{ZnO}$ for evaporation. The source of $\mathrm{ZnO}$ (99.9\% pure) as a powder was loaded onto a tungsten crucible in the vacuum. Prior to deposition, the $\mathrm{ZnO}$ and tungsten boat were cleaned with alcohol to remove any contamination and dried using nitrogen gas. The vacuum chamber was evacuated to $3 \times$ $10^{-5}$ Torr before the source was heated. The tungsten boat was heated using 3.0 A direct current for 10 seconds to melt the $\mathrm{ZnO}$. The current was increased slowly to $8.0 \mathrm{~A}$ until all of the $\mathrm{ZnO}$ evaporated. The substrate was removed after waiting for a few minutes for the chamber to cool down. Films of different thicknesses were prepared through different individual evaporation sessions. The thicknesses of $\mathrm{ZnO}$ thin films are found using an optical reflectometer (model: Filmetrics F20). The crystallographic structure of $\mathrm{ZnO}$ thin films deposited on PET substrates was determined using a high-resolution X-ray diffractometer system (model: PANalytical X'Pert PRO MRD PW3040). The compositions of the $\mathrm{ZnO}$ thin films were estimated with energy dispersive X-ray analysis (EDX) (model: JSM-6460 LV).

The surface morphology of $\mathrm{ZnO}$ thin films was studied using an atomic force microscope (AFM; model: ULTRA Objective). The optical properties of $\mathrm{ZnO}$ thin films deposited on PET substrates were characterized using a UV spectrophotometer (model: U-2000 HITACHI).

\section{Results and Discussion}

3.1. Structural Characterizations. Figure 1 shows the XRD spectra for the vacuum-evaporated $\mathrm{ZnO}$ thin films on PET substrates. This spectrum was obtained at room temperature for a $\mathrm{ZnO}$ thin film with a thickness of $300 \mathrm{~nm}$. The main peak corresponding to the PET substrate was observed at $2 \theta$ angle $26^{\circ}$ [13-16]; it had a very high intensity. According to Figure 1, all peaks of the $\mathrm{ZnO}$ thin films can be well indexed to the hexagonal wurtzite structure of $\mathrm{ZnO}$ (JCPDS Card no. 01-089-0510, $a=0.325 \mathrm{~nm}$ and $c=0.521 \mathrm{~nm}$ ).

Figure 2 shows the EDX results for $\mathrm{ZnO}$ thin films deposited on PET substrates. EDX analysis confirms the composition of $\mathrm{Zn}$ and $\mathrm{O}$ in the $\mathrm{ZnO}$ film. The presence of the carbon peak in the spectrum is due to the PET substrate. 


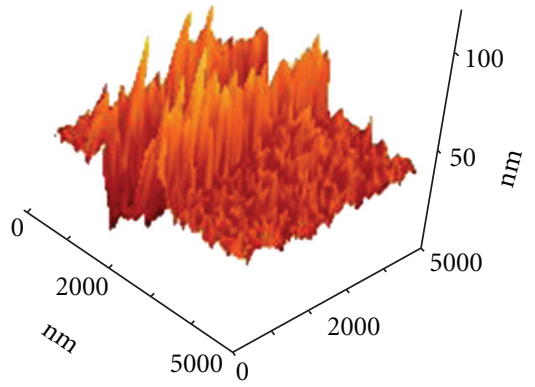

(a)

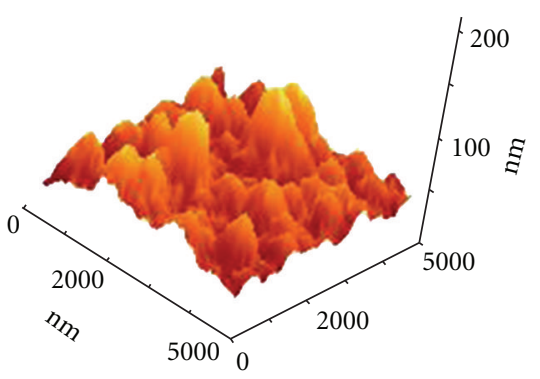

(b)

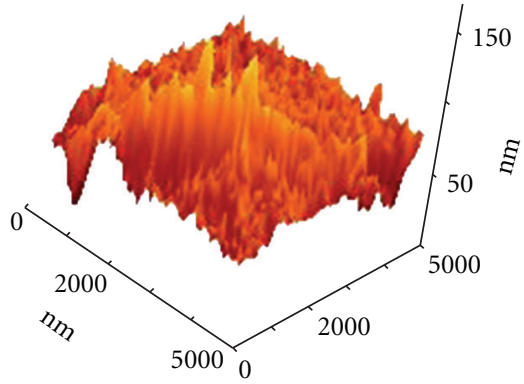

(c)

FIgUre 3: AFM analysis of $\mathrm{ZnO}$ films deposited on PET substrates with different thicknesses.

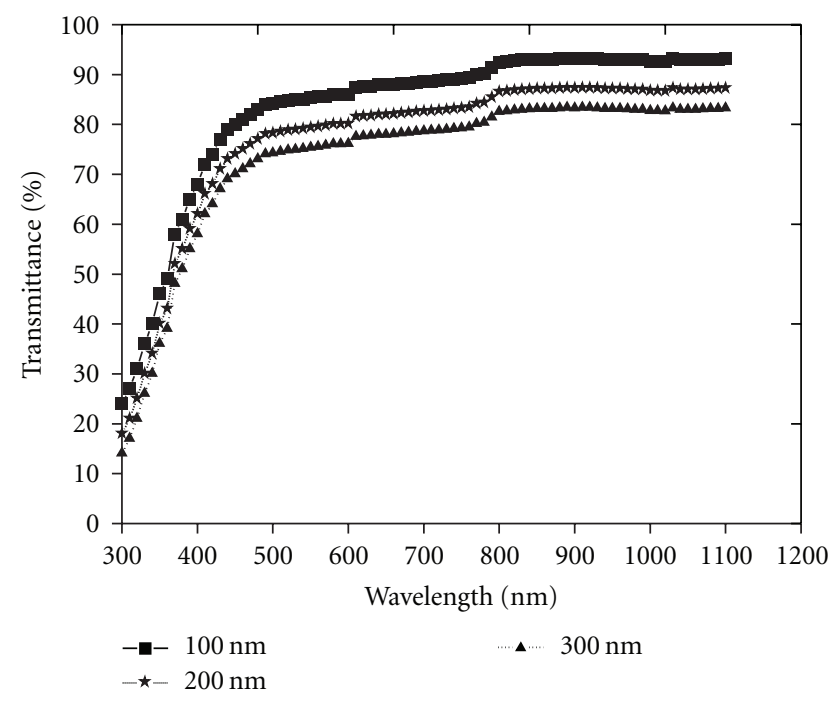

Figure 4: Transmission spectra of $\mathrm{ZnO}$ thin films of varying thicknesses.

AFM images of the surface morphologies of $\mathrm{ZnO}$ thin films deposited on PET substrates are shown in Figure 3. The surfaces of the product $\mathrm{ZnO}$ thin films were obviously smooth. The root mean square (RMS) surface roughness of the films was $13.07 \mathrm{~nm}, 15.36 \mathrm{~nm}$ and $16.23 \mathrm{~nm}$ for films with thicknesses of 100 to $300 \mathrm{~nm}$, respectively. These results indicate that the surface quality of $\mathrm{ZnO}$ thin films on PET substrate improved as the film thickness decreased. In all cases, the conical features clearly seen on the film surface were the cause of the surface roughness. It is important to note here that surface smoothness is a highly desired parameter for coatings that are used for optical applications because it reduces the reflection loss due to roughnessinduced surface scattering [17].

3.2. Optical Characterization. The effect of thickness on the optical properties of $\mathrm{ZnO}$ films has been studied. The optical transmittance spectra of $\mathrm{ZnO}$ thin films deposited on PET substrates of different thicknesses are shown in Figure 4. All these films demonstrate good optical transmittance

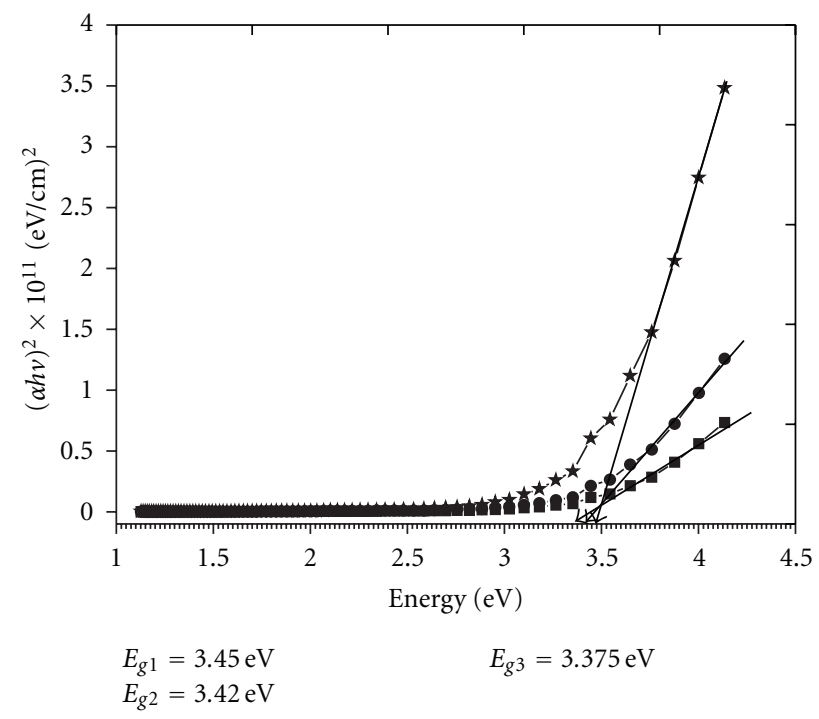

Figure 5: A plot of $(\alpha h \nu)^{2}$ as a function of photon energy for $\mathrm{ZnO}$ thin films deposited on PET substrates with different thicknesses.

(over $80 \%$ ) in the visible and near-infrared range. Their high transmission in the visible range makes these films excellent candidates for transparent window materials in solar cells. The transmission of $\mathrm{ZnO}$ thin films decreased as the thickness increased; similar behavior involving a decrease in the transmission of the films as the film thickness increases has been reported in the literature $[18,19]$.

It is well known that $\mathrm{ZnO}$ is a direct gap semiconductor. The optical band gap $E_{g}$ was determined by analyzing the optical data with the expression for the optical absorbance $\alpha$ and the photon energy $h \nu[20]$ :

$$
\alpha h \nu=k\left(h v-E_{g}\right)^{1 / 2},
$$

where $h$ is the Planck constant, $v$ is the radiation frequency, and $k$ is a constant. The optical band gap value $\left(E_{g}\right)$ can be obtained by plotting $(\alpha h \nu)^{2}$; $h \nu$ is the photon energy, as shown in Figure 5. As the film thickness increased from 100 to $300 \mathrm{~nm}$, the value of the optical band gap gradually decreased from 3.45 to $3.375 \mathrm{eV}$, similar to other reports [21]. 


\section{Conclusion}

$\mathrm{ZnO}$ thin films with various thicknesses were prepared on PET substrates by the thermal evaporation technique. The characteristics of $\mathrm{ZnO}$ thin films were investigated by various tools. The XRD patterns of the films deposited on PET substrates showed the proper formation of hexagonal $\mathrm{ZnO}$. From AFM images, it was found that the root mean square roughness of the film surface increased as the film thickness increased. The optical band gap values of $\mathrm{ZnO}$ thin films decreased as the film thickness increased. The optical properties that were observed for uniform films of $\mathrm{ZnO}$ on PET substrates indicate that they may be used as window layers in solar cells.

\section{Acknowledgments}

This paper was supported by the Nano-Optoelectronic Research Laboratory (N.O.R) of the School of Physics, Universiti Sains Malaysia (USM) under Grant no. 1001/PFIZIK/ 814010. M. G. Faraj wishes to thank the Ministry of Higher Education of Kurdistan Regional Government/Iraq and University of Koya/Iraq for awarding him a scholarship to pursue his Ph.D. abroad.

\section{References}

[1] P. F. Yang, H. C. Wen, S. R. Jian, Y. S. Lai, S. Wu, and R. S. Chen, "Characteristics of $\mathrm{ZnO}$ thin films prepared by radio frequency magnetron sputtering," Microelectronics Reliability, vol. 48, no. 3, pp. 389-394, 2008.

[2] J. S. Wellings, N. B. Chaure, S. N. Heavens, and I. M. Dharmadasa, "Growth and characterisation of electrodeposited ZnO thin films," Thin Solid Films, vol. 516, no. 12, pp. 3893 3898, 2008.

[3] D. Kim, T. Shimomura, S. Wakaiki, T. Terashita, and M. Nakayama, "Photoluminescence properties of high-quality $\mathrm{ZnO}$ thin films prepared by an RF-magnetron sputtering method," Physica B, vol. 376-377, no. 1, pp. 741-744, 2006.

[4] T. Maruyama and J. Shionoya, "Zinc oxide thin films prepared by chemical vapour deposition from zinc acetate," Journal of Materials Science Letters, vol. 11, no. 3, pp. 170-172, 1992.

[5] G. Srinivasan and J. Kumar, "Optical and structural characterisation of zinc oxide thin films prepared by sol-gel process," Crystal Research and Technology, vol. 41, no. 9, pp. 893-896, 2006.

[6] S. J. Lim, S. Kwon, and H. Kim, "ZnO thin films prepared by atomic layer deposition and rf sputtering as an active layer for thin film transistor," Thin Solid Films, vol. 516, no. 7, pp. 15231528, 2008.

[7] R. Ayouchi, D. Leinen, F. Martín, M. Gabas, E. Dalchiele, and J. R. Ramos-Barrado, "Preparation and characterization of transparent $\mathrm{ZnO}$ thin films obtained by spray pyrolysis," Thin Solid Films, vol. 426, no. 1-2, pp. 68-77, 2003.

[8] L. Zhao, J. Lian, Y. Liu, and Q. Jiang, "Structural and optical properties of $\mathrm{ZnO}$ thin films deposited on quartz glass by pulsed laser deposition," Applied Surface Science, vol. 252, no. 24, pp. 8451-8455, 2006.

[9] O. A. Fouad, A. A. Ismail, Z. I. Zaki, and R. M. Mohamed, "Zinc oxide thin films prepared by thermal evaporation deposition and its photocatalytic activity," Applied Catalysis B, vol. 62, no. 1-2, pp. 144-149, 2006.

[10] A. N. Banerjee, C. K. Ghosh, K. K. Chattopadhyay et al., "Lowtemperature deposition of $\mathrm{ZnO}$ thin films on PET and glass substrates by DC-sputtering technique," Thin Solid Films, vol. 496, no. 1, pp. 112-116, 2006.

[11] M. Garganourakis, S. Logothetidis, C. Pitsalidis, D. Georgiou, S. Kassavetis, and A. Laskarakis, "Deposition and characterization of PEDOT/ZnO layers onto PET substrates," Thin Solid Films, vol. 517, no. 23, pp. 6409-6413, 2009.

[12] Y. S. Park, H. K. Kim, S. W. Jeong, and W. J. Cho, "Highly flexible indium zinc oxide electrode grown on PET substrate by cost efficient roll-to-roll sputtering process," Thin Solid Films, vol. 518, no. 11, pp. 3071-3074, 2010.

[13] M. G. Faraj, K. Ibrahim, M. H. Eisa, M. K. M. Ali, and F. Azhari, "Investigation on molybdenum thin films deposited by DC-sputtering on polyethylene terephthalate substrate," International Journal of Polymeric Materials, vol. 59, no. 8, pp. 622-627, 2010.

[14] Q. Zhou, Z. Ji, B. Hu, C. Chen, L. Zhao, and C. Wang, "Low resistivity transparent conducting $\mathrm{CdO}$ thin films deposited by DC reactive magnetron sputtering at room temperature," Materials Letters, vol. 61, no. 2, pp. 531-534, 2007.

[15] C. Guillén and J. Herrero, "Comparison study of ITO thin films deposited by sputtering at room temperature onto polymer and glass substrates," Thin Solid Films, vol. 480-481, pp. 129-132, 2005.

[16] S. Gupta, M. Dixit, M. Baboo, K. Sharma, and N. S. Saxena, "Thickness-dependent mechanical behaviour of aluminiumcoated polyethylene terephthalate (PET) films," Thin Solid Films, vol. 48, pp. 1333-1337, 2009.

[17] N. Tigau, V. Ciupina, and G. Prodan, "Structural, optical and electrical properties of $\mathrm{Sb}_{2} \mathrm{O}_{3}$ thin films with different thickness," Journal of Optoelectronics and Advanced Materials, vol. 8, no. 1, pp. 37-42, 2006.

[18] R. K. Gupta, K. Ghosh, R. Patel, and P. K. Kahol, "Effect of thickness on optoelectrical properties of Mo-doped indium oxide films," Applied Surface Science, vol. 255, no. 5, pp. 30463048, 2008.

[19] R. K. Gupta, K. Ghosh, and P. K. Kahol, “Thickness dependence of optoelectrical properties of tungsten-doped indium oxide films," Applied Surface Science, vol. 255, no. 21, pp. 89268930, 2009.

[20] J. Tauc, vol. 1974, Plenum Press, New York, NY, USA, Amorphous and Liquid Semiconductors.

[21] X. Hao, J. Ma, D. Zhang et al., "Thickness dependence of structural, optical and electrical properties of $\mathrm{ZnO}$ :Al films prepared on flexible substrates," Applied Surface Science, vol. 183, no. 1-2, pp. 137-142, 2001. 

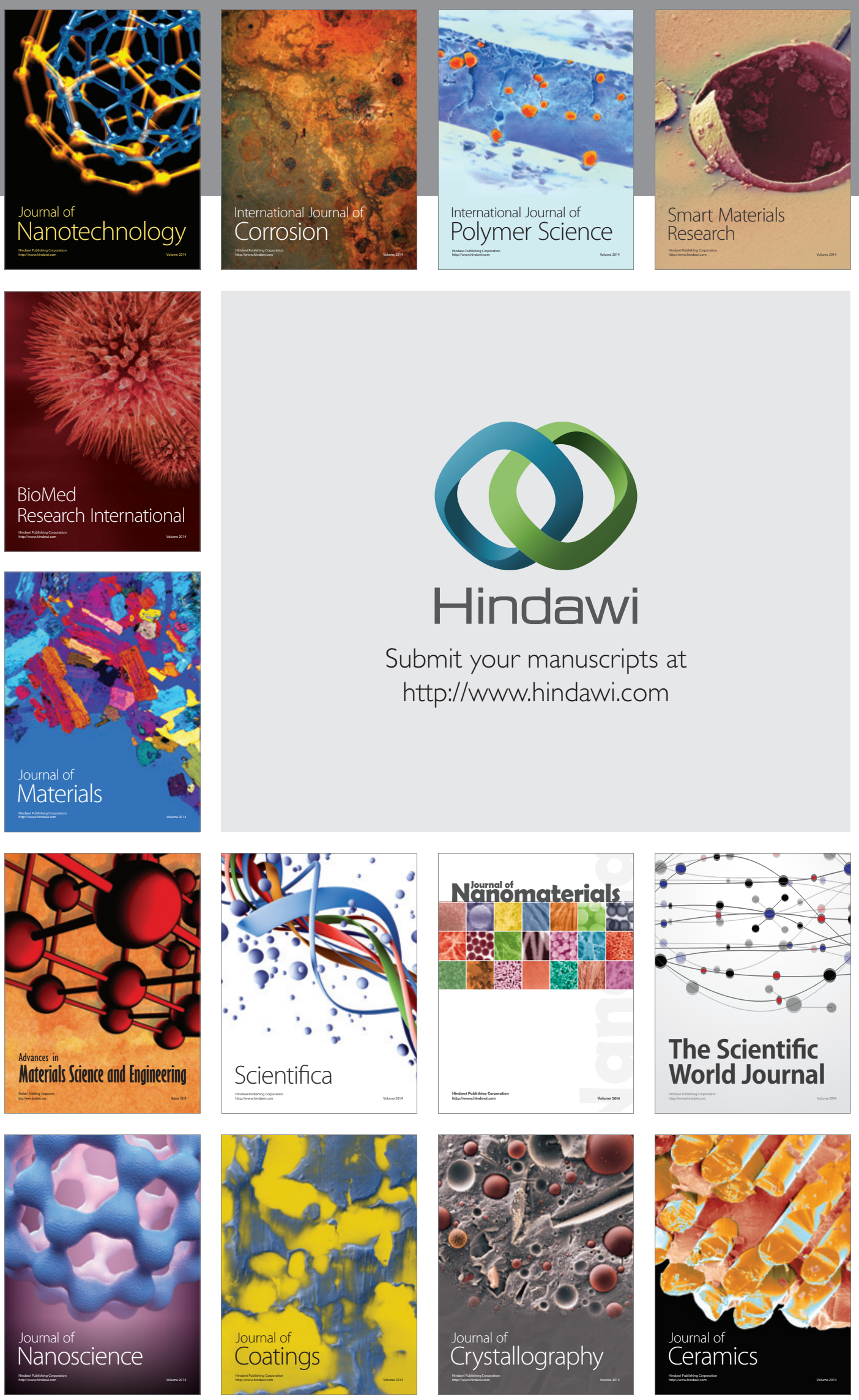

The Scientific World Journal

Submit your manuscripts at

http://www.hindawi.com

\section{World Journal}

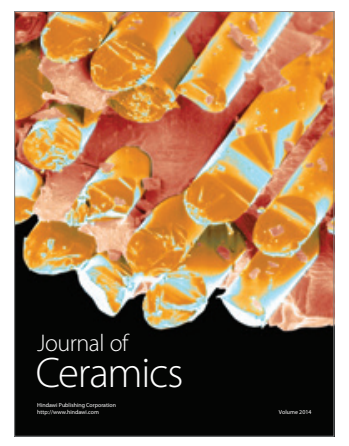

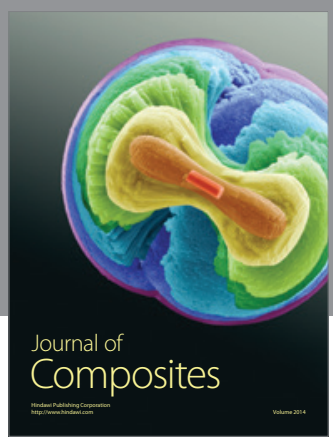
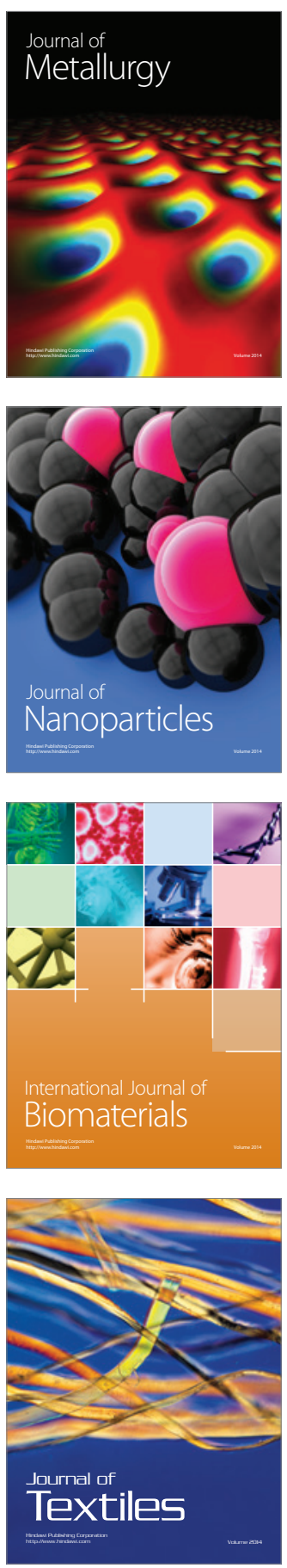